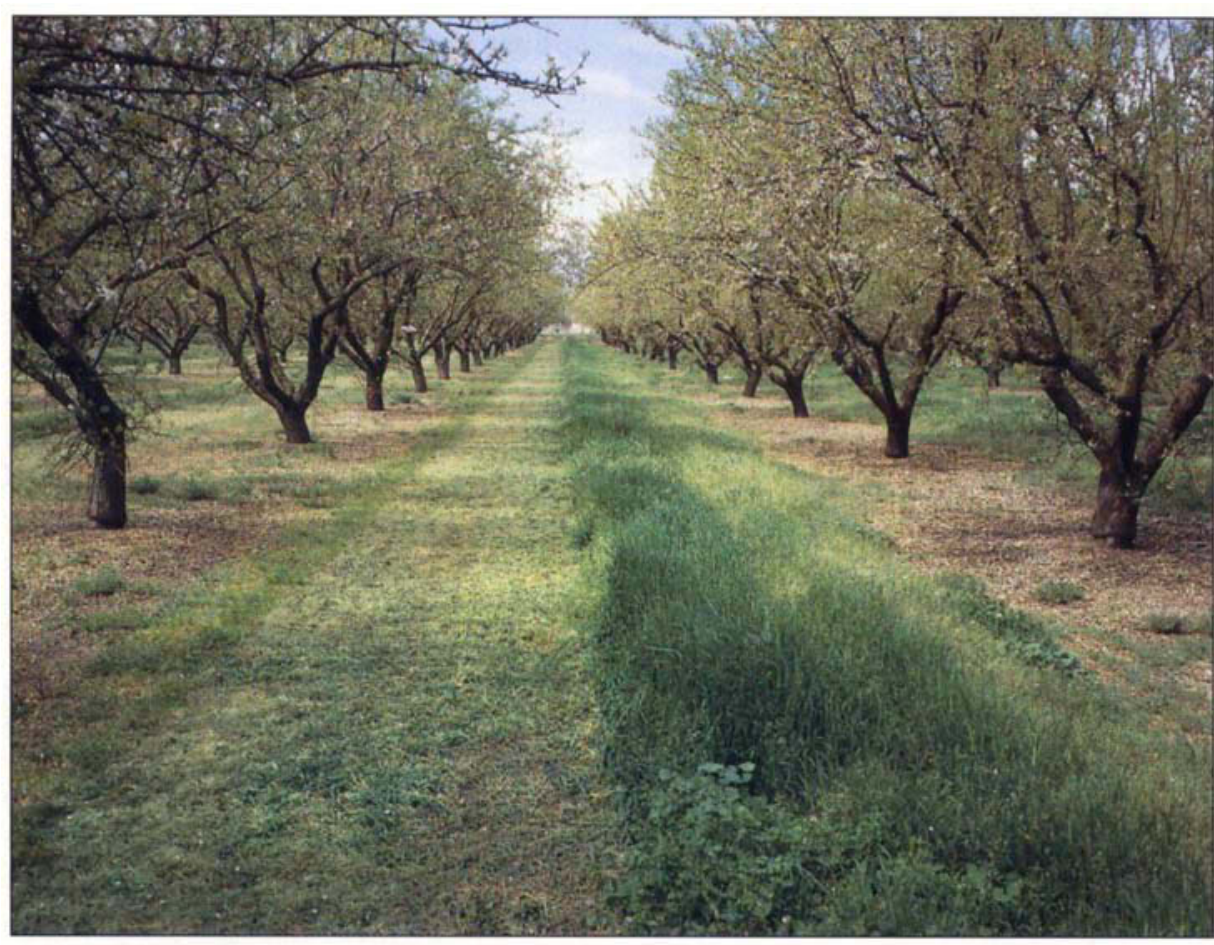

\title{
Almond growers reduce pesticide use in Merced County field trials
}

\author{
Lonnie C. Hendricks
}

California almond growers commonly use organophosphate pesticides, which can be disruptive to biological control. Sprays during the spring and summer kill beneficial arthropods, including parasitic and predatory insects and spiders. In addition, pesticides have been detected by Cal EPA in winter fog and in runoff water flowing into the rivers of the San Joaquin Valley, which may lead to further restrictions in pesticide use. However, some almond growers are able to grow nuts with low insect damage without using toxic insecticide sprays. This article reports the results of a 6-year study, begun in 1988, of three almond orchards in Merced County to identify grower practices that permit reduced pesticide use.
Many almond growers encourage the survival of beneficial insects and spiders in their orchards by reducing or eliminating the use of toxic pesticides. Growers also plant cover crops that host insects such as aphids that provide food for beneficials. A lush cover crop will host an abundance of prey insect species, and the predators and parasites that feed on these insects will enhance control of the almond pests. This change in orchard management is especially evident in the Central San Joaquin Valley.

The twospotted spider mite is the primary web-spinning summer mite in this area. Spider mite outbreaks often follow disruptive sprays, and control is usually not required in orchards that are unsprayed or that are sprayed only with non-disruptive insecticides such as Bacillus thuringiensis (Bt). The western orchard predator mite

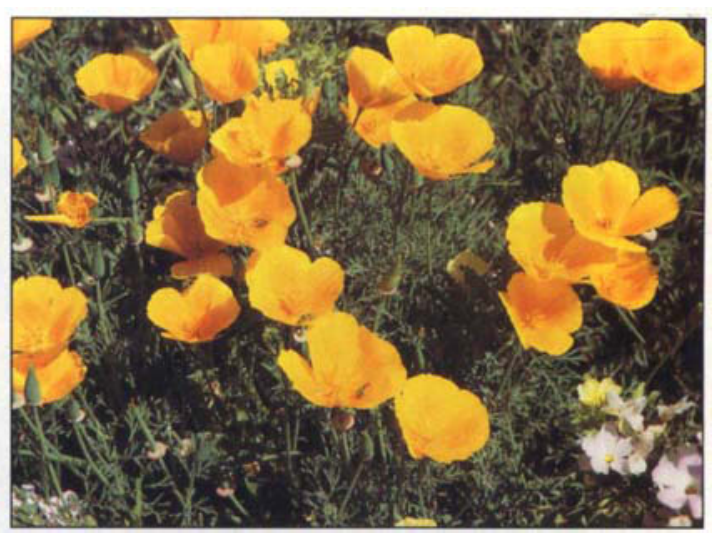

Above, California popples and mixed wildflowers planted along the orchard's border provide nectar and pollen to improve the blological diversity of insects.

Left, in this low-input orchard, halves of the middles were mowed on an alternating basis to provide a continuous habitat for beneficial insects.

(Metaseiulus occidentalis), the sixspotted thrips (Scolothrips sexmaculatus) and other predators usually control spider mites very well under favorable conditions. These conditions include good moisture conditions, low dust levels, elimination of disruptive sprays, and good cover-crop management to provide an insectary for beneficials. Scale can be controlled with dormant sprays, but scale is seldom a problem in unsprayed almonds.

A study was begun in 1988 in Merced County to learn why some almond growers are able to grow nuts with low insect-damage levels without using toxic insecticide sprays. The study was designed to learn what grower practices allow reduction of pesticide use in almonds. A secondary goal was to measure or monitor other components such as numbers and types of arthropods in the orchard, tree nutrition, soil organic matter and earthworms in each orchard.

\section{Whole-farm comparison}

This project was designed as a whole-farm comparison project with 20 acres in each comparison block. Replication was not attempted because replication within one orchard would require very large plot sizes to minimize the effects of pest and beneficial insect migration, and this amount of acreage was not available. Furthermore, replication within one orchard would require the orchard owner/ manager to be skillful in both conventional and organic methods without 


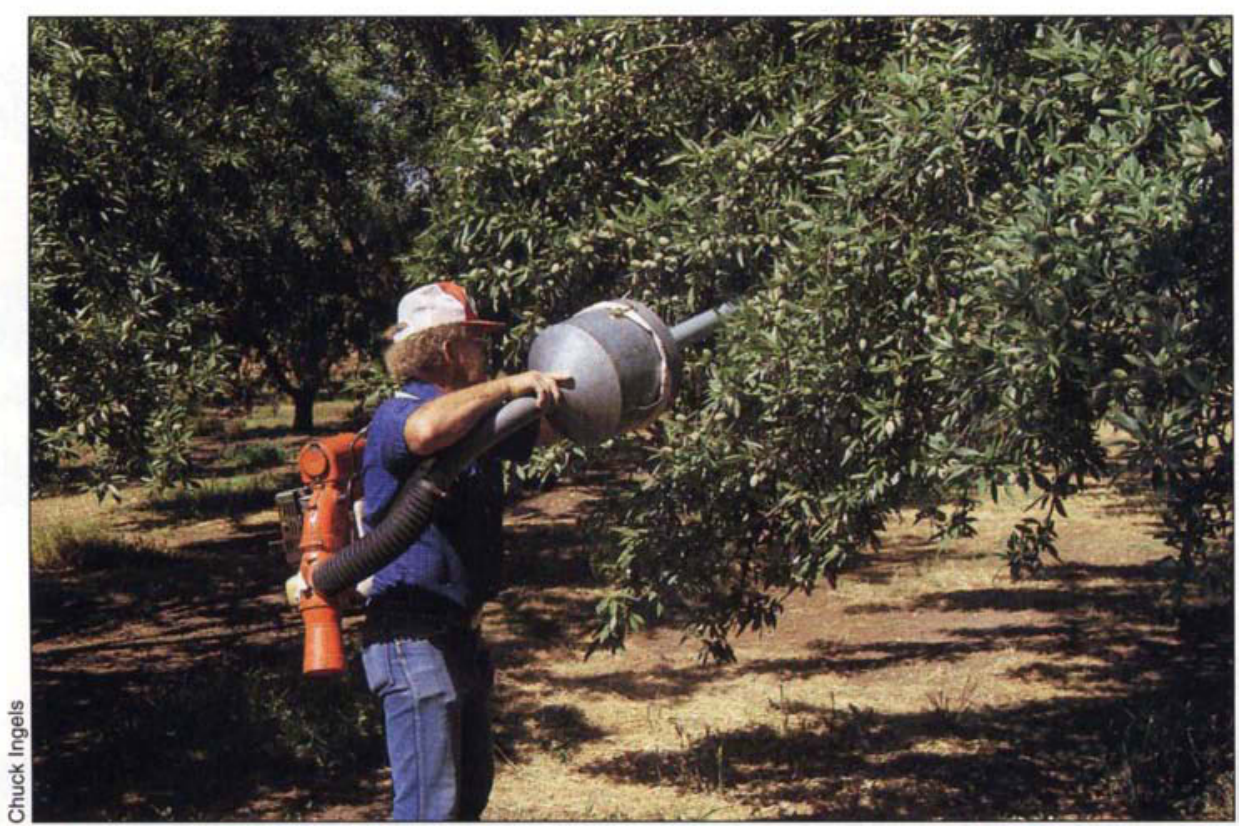

Beneficlal insects were Inventoried by vacuuming the follage of the cover crops and trees.

interjecting some bias into the management process. Therefore the wholefarm comparison method was chosen.

This was observational and dependent upon the growers to maintain reasonably consistent practices. The organic orchard remained strictly organic and is certified organic. The lowinput orchard started conventional and transitioned to no insecticide use, but continued fungicides, fertilizers, some herbicides, and so on. The conventional remained conventional, but did use Bt at times, as is true of the industry. I did not specify which treatments could or should be made since my desire was to see the three divergent methods at work. This was much more flexible than a rigid replicated trial would be.

Three orchards planted with alternating rows of 'Nonpareil' and 'Carmel' cultivars were used for this comparison. The first orchard is a certified organic orchard, planted in 1981, which in this report is designated "organic." The organic orchard had a dense cover of 'Lana' vetch and ripgut bromegrass, which was mowed in May and disked before harvest. During the study this orchard was converted to mowing alone and was not disked before harvest. This orchard has not been sprayed with insecticides throughout its life, and no herbicides or fungicides have been used during the years of this comparison.
The second orchard, called the "low-input" orchard, which was planted in 1980, was farmed as a conventional orchard, using an organophosphate plus oil dormant spray and a May or July (hull split) organophosphate pesticide application. This grower eliminated the insecticide spraying after the first year of the study. Since 1990 no insecticides have been used in this orchard, but herbicides, nutrient sprays, and fungicides are still used. The organic and low-input orchards are adjacent to one another, and both orchards are flood-irrigated.

The low-input orchard had a sparse resident vegetation cover crop at the beginning of the test in 1988 . This cover was chemically mowed before almond bloom for frost protection and closely flail-mowed through the spring and summer. Beginning in 1989 the vegetation was allowed to grow tall and was alternate-row mowed until June or early July, when close mowing for harvest preparation begins. Alternate row middles were mowed on one date, then the remaining middles were mowed 2 to 3 weeks later. This provided a continuous habitat for beneficials.

A third orchard, located a quartermile north of the low-input orchard, was added to the project in 1989 . This sprayed with a dormant spray of insecticide and oil and a May or a hullorchard has remained conventionally split spray. This flood-irrigated 'Nonpareil' and 'Carmel' orchard was planted in 1975. It is designated as conventional and was added for two reasons. First, it was a heavily sprayed and clean-disked orchard with severe worm problems. And second, the lowinput orchard was in transition to no insecticide spraying and much better cover-crop management. Two very important requirements for organic and low-input culture are the use of cover crops to promote and protect beneficials and no use of toxic insecticides that disrupt biocontrol. The conventional orchard had no cover crop and used toxic sprays, and further, it had a worm problem to solve. It replaced the low-input orchard, which had been conventional. The conventional orchard was converted from disking to mowed resident vegetation in 1990, and a cover crop of vetch, clovers and grasses was planted in 1993.

Navel orangeworm. The navel orangeworm, Amyelois transitella (NOW), is the major pest of almond, and is responsible for the majority of the inedible nuts (rejects) at harvest. In evaluating these orchards, counts of overwintering almond nuts remaining in the trees (mummies) were done as a method of estimating the potential threat of navel orangeworm to the following year's crop. Navel orangeworm overwinters as an immature larva in mummies, and feeds on these mummies during the winter and spring. Sanitation by removing and destroying mummies is extremely important in managing NOW; the goal is winter counts of less than one to two mummies per tree. Navel orangeworm egg-laying activity was monitored with the use of four Pherocon IV egg traps per orchard. Eggs were counted twice per week from March until harvest.

Peach twig borer. The peach twig borer, Anarsia lineatella (PTB), can be a major pest in some years, especially if the PTB hatch coincides with hull split. Peach twig borer flights were monitored with two Pherocon $1 C$ traps with Trece septa per orchard, and were checked twice per week. Peach twig borer pheromone traps are used to determine flight timing, but cannot be used reliably to estimate in- 
sect populations. Percentages of inedible nuts (rejects) due to NOW and PTB damage at harvest were determined by sampling 2,000 nuts directly from the harvest windrows. Samples were hand-cracked and the type of damage determined by inspection of the feeding damage.

Spider mites. The twospotted spider mite, Tetranychus urticae, is the primary web-spinning summer mite in this area. It can cause defoliation when approximately $50 \%$ of the leaves are infested. In this comparison, spider mites were monitored by collecting 50 leaves at random through each orchard and counting mites to determine the number of mites per 50 leaves.

San Jose scale. San Jose scale, Quadraspidiotus perniciosus, can cause the death of spurs and shoots. Twentyfive watersprouts were collected per orchard during the dormant period. The number of live and dead scale per 6-inch portion of the base of each watersprout was counted under a binocular microscope.

Beneficial insects. Beneficial insects were collected for a timed period in both the cover crops and the trees with a vacuum device called a d-VAC. Collections were made by vacuuming the foliage up to 7 or 8 feet and by vacuuming the orchard floor while walking through the test area. Counts in the cover crops were also made with sweep nets, using insect numbers per 25 sweeps while walking through the test blocks. None of the three orchards in this whole-orchard comparison has had releases of beneficial insects, so these were not a factor in the counts. Some of the insects that were being monitored were the convergent ladybird beetle (Hippodamia convergens), the lacewings (Hemerobius spp. and Chrysopa spp.), assassin bugs (Zelus spp.), big-eyed bugs (Geocoris spp.) and parasitic wasps. Observations indicate that orchards that are not disrupted by harsh pesticides have a very high level of spider activity. Spiders have recently been recognized as good generalist predators in vineyards, but no counts of spiders were made in this study.

Soil organic matter and fertility. Soil organic matter levels were moni- tored as a way to estimate and compare the soil fertility of the three orchards. It is generally accepted as fact that a soil with a high organic matter level is more fertile and more biologically active than a similar soil with low organic matter. The organic matter in these orchards is largely from residues of the cover crops, but organic matter is also derived from shredded prunings, manure or compost, leaves, hulls and other plant residues. Composite soil samples for organic matter analysis were collected from a number of random sites in each orchard from surface to 6-inch depth and 6- to 12-inch depth, during the spring and summer months. Early in the comparison it was noted that the highest organic matter levels were usually found in April, and that the more significant changes occurred in the top 6 inches. In later years most samples were taken only from the surface to 6-inch depth.

Leaves were collected annually in June or July and analyzed for levels of nitrogen, potassium, sodium, chloride, zinc and boron. Leaf analysis was done to monitor the nutrients to detect any deficiencies that could adversely alter the orchard comparisons. Grower treatments were made periodically to maintain acceptable nutrient levels, but no applications were made as part of this comparison.

Earthworms. Earthworms are a good measure of soil health and biological activity in the soil. They are important in the recycling of organic material such as cover-crop residues, leaves, shredded prunings and manure or compost. They also leave nutrient-rich worm castings, and they aerate the soil as they burrow. Measurements of earthworm numbers in the experimental orchards were made by using a very mild solution of formalin or powdered mustard poured into the soil inside four observation rings per orchard. The observation rings are made from the top half of 5gallon plastic buckets. This caused the earthworms in the immediate area to come to the surface where they could be counted, collected and identified.

\section{Study results}

Rejects due to worm damage at harvest. Rejects at harvest are commonly caused by navel orangeworm (NOW) and peach twig borer (PTB).

\begin{tabular}{lllccccc}
\multicolumn{7}{c}{ TABLE 1. Almond kernel damage from NOW and PTB } \\
\hline \hline \multirow{2}{*}{ Orchard } & \multicolumn{7}{c}{ Rejects due to NOW and PTB } \\
\cline { 2 - 9 } & Pest & 1988 & 1989 & 1990 & 1991 & 1992 & 1993 \\
\hline \multirow{2}{*}{ Organic } & NOW & 0.9 & 1.0 & 0.3 & 0.2 & 1.8 & 0.4 \\
& PTB & 1.9 & 0.2 & 0.1 & 0.0 & 0.0 & 1.7 \\
Low-input & NOW & $2.4^{*}$ & $1.6^{*}$ & 1.5 & 0.2 & 1.6 & 0.8 \\
\multirow{2}{*}{ Conventional } & PTB & $0.3^{*}$ & $0.2^{*}$ & 0.9 & 0.4 & 0.0 & 1.9 \\
& NOW & - & 8.8 & 6.0 & 1.0 & 4.3 & 0.7 \\
& PTB & - & 0.7 & 0.5 & 0.3 & 0.0 & 1.5 \\
\hline
\end{tabular}

"Dormant spray 1988 and 1989 only.

TABLE 2. Mite species associated with almond trees in June and July 1993

\begin{tabular}{lccccc}
\hline \hline & \multicolumn{5}{c}{ Average } \\
\cline { 2 - 6 } Orchard & $\begin{array}{c}\text { Brown } \\
\text { almond }\end{array}$ & $\begin{array}{c}\text { European } \\
\text { red }\end{array}$ & $\begin{array}{c}\text { Two- } \\
\text { spotted }\end{array}$ & Tydeid & $\begin{array}{c}\text { M. occidentalis } \\
\text { predator }\end{array}$ \\
\hline Organic & 3.8 & 4.8 & 1.4 & 20.6 & 11.2 \\
Low-input & 7.5 & 1.0 & 6.8 & 10.0 & 6.8 \\
Conventional* & 0.2 & 0.0 & 0.0 & 0.0 & 0.6 \\
\hline
\end{tabular}

"Following mite control spray.

TABLE 3. Average number of live San Jose scale on 6-inch basal portion of almond watersprouts in late winter

\begin{tabular}{lccccc}
\hline \hline & \multicolumn{5}{c}{ SJS/shoot on 25 shoots } \\
\cline { 2 - 6 } Orchard & Feb. & Feb. & Feb. & Feb. & Feb. \\
\hline Organic & 1989 & 1990 & 1991 & 1992 & 1993 \\
Low-input & 0.3 & 0.4 & 0.2 & 0.3 & 0.2 \\
Conventional & $0.1^{*}$ & $1^{*}$ & 5.0 & 0.8 & 2.9 \\
\hline "Following dormant sprays. & - & $0.5^{*}$ & $0.4^{*}$ & & $1^{*}$ \\
\hline
\end{tabular}


Gummy and shriveled kernels are also rejects, but are not related to insecticide use. Hand-cracked samples of nuts from windrows at harvest showed very similar reject levels for the organic and low-input orchards over the 6 years of the comparisons (table 1). Although the differences were small, the organic orchard had lower reject levels in 4 of the 6 years of the trial.

In the conventional orchard, rejects due to NOW and PTB were extremely high at $9.5 \%$ in the 1989 harvest. This was attributed to the high survival of NOW in the 50 to 60 mummies per tree. In succeeding years this grower has adopted an aggressive program of mummy removal and destruction and the harvest grades have improved greatly, even though the insecticide spray program has remained quite constant. Rejects have been reduced to an acceptable level, but have not been lower than the organic orchard in any of the 5 years.

Twospotted spider mite. In the organic and low-input orchards, spider mites have not increased to damaging levels in the absence of pesticides (table 2). The results have been similar in each year of the study. The only severe mite outbreak was in 1990 in the conventional orchard following a disruptive summer spray of synthetic pyrethroid for NOW control. Tydeid mites have been very prominent in the organic orchard, and have been found in small numbers in the low-input orchard. The Tydeid mite can be beneficial, because it does not damage almond leaves and is an alternative food source for mite predators.

San Jose scale. The organic orchard has never had sufficiently high numbers of San Jose scale to cause spur and shoot damage. In 1993 scale counts increased slightly in the lowinput and conventional orchards, but remained virtually the same as in the previous 4 years in the organic orchard (table 3). This is most likely the result of natural parasitism and predation. At least two resident wasp parasites have been reported to parasitize scale, and generalist predators feed on scale as well.

The low-input orchard had low to moderate San Jose scale numbers in the first 3 years of the observations, but scale levels stabilized at a moderate level after insecticide use was terminated. Careful monitoring of scale insects is very important, because San Jose scale can be very damaging if populations become too high. Winter scale counts of five per 6-inch shoot have been well below the level that would cause severe damage. The conventional orchard receives annual winter sprays, which keep scale levels low.

\section{Beneficial predators and para-}

sites. Predator and parasite monitoring by $\mathrm{d}-\mathrm{VAC}$ or an insect sweep net showed ladybird beetle numbers high in the organic orchard and parasitic

TABLE 4. Average number of convergent ladybird beetles per 25 sweeps in 1993

\begin{tabular}{|c|c|c|c|c|c|c|c|c|c|c|c|c|c|c|c|c|}
\hline Orchard & $4 / 22$ & $4 / 30$ & $5 / 7$ & $5 / 14$ & $5 / 22$ & $6 / 4$ & $6 / 11$ & $6 / 18$ & $6 / 25$ & $6 / 30$ & $7 / 1$ & $7 / 9$ & $7 / 17$ & $7 / 31$ & $8 / 18$ & Total \\
\hline Organic & 5 & 13 & 3 & 7 & 4 & 2 & 0 & 0 & 0 & 1 & 0 & 0 & 0 & 0 & 0 & 35 \\
\hline Low-input & 0 & 4 & 2 & 2 & 0 & 2 & 0 & 0 & 0 & 1 & 0 & 0 & 1 & 0 & 0 & 12 \\
\hline Conventional & 6 & 0 & 1 & 3 & 2 & 1 & 0 & 0 & 0 & 0 & 0 & 0 & 0 & 0 & 0 & 13 \\
\hline \multicolumn{17}{|c|}{ TABLE 5. Average number of beneficial wasps per 25 sweeps in 1993} \\
\hline Orchard & $4 / 22$ & $4 / 30$ & $5 / 7$ & $5 / 14$ & $5 / 22$ & $6 / 4$ & $6 / 11$ & $6 / 18$ & $6 / 25$ & $6 / 30$ & $7 / 1$ & $7 / 9$ & $7 / 17$ & $7 / 31$ & 8/18 & Total \\
\hline Organic & 4 & 5 & 2 & 4 & 0 & 1 & 3 & 6 & 3 & 1 & 0 & 2 & 3 & 0 & 0 & 34 \\
\hline Low-input & 0 & 0 & 1 & 4 & 3 & 4 & 0 & 2 & 1 & 2 & 2 & 6 & 3 & 0 & 2 & 30 \\
\hline Conventional & 0 & 0 & 0 & 3 & 2 & 2 & 0 & 0 & 0 & 5 & 0 & 0 & 0 & 0 & 0 & 12 \\
\hline
\end{tabular}

TABLE 6. Organic matter in surface 6 inches of soil in April

\begin{tabular}{lccccc}
\hline \hline Orchard & 1989 & 1990 & 1991 & 1992 & 1993 \\
\hline & $\ldots \ldots \ldots \ldots \ldots \ldots \ldots \ldots . . . \%$ & $\ldots \ldots \ldots \ldots \ldots \ldots \ldots \ldots \ldots . .$. \\
Organic & 1.4 & 1.1 & 1.1 & $0.9^{*}$ & 1.8 \\
Low-input & 0.5 & 1.0 & 1.4 & $0.9^{*}$ & 1.5 \\
Conventional - & 1.0 & 0.8 & $0.7^{*}$ & 0.9 \\
\hline
\end{tabular}

- June sample only 1992.
TABLE 7. Average number of earthworms per observation ring in three almond orchards

\begin{tabular}{lccccc}
\hline \hline & \multicolumn{3}{c}{1993} & \multicolumn{3}{c}{1994} \\
\hline Orchard & $\mathbf{5 / 1 5}$ & $\mathbf{6} / 7$ & $\mathbf{7 / 1 2}$ & $\mathbf{4} / \mathbf{2 5}$ & $\mathbf{5 / 9}$ \\
Organic & 9 & 15 & 8 & 6 & 12 \\
Low-input & 0 & 28 & 9 & 20 & 14 \\
Conventional & 0 & 0 & 0 & 0 & 0.3 \\
\hline
\end{tabular}


conventional orchard remained at $1.0 \%$ or less organic matter through 1993. In 1993 the organic matter increased in all orchards. The organic matter levels build in the spring to a peak in April to May. Then, as decomposition takes place and nutrients are released, the level drops to a low point in late summer.

Nutrients are supplemented in each orchard to keep the essential elements in a sufficient range. The irrigation water in this area supplies these orchards with approximately 100 pounds of nitrogen per acre through the normal flood irrigations. No nutrient treatments were made as part of this experiment.

Earthworms. Earthworm numbers were measured periodically in these orchards, especially in 1993 and 1994 (table 7). Both the organic orchard with a dense vetch cover, and the lowinput orchard with a lush resident vegetation cover have very high numbers of earthworms. Two species were found and identified by Dr. Matthew Werner, soil ecologist at UC Santa Cruz, as Aporrectodea turgida and Microscolex dubius. The conventional orchard, which had been disked for many years, had no earthworms in 1993, and still has only a very few earthworms in 1994, after 2 years of cover cropping. This lack of earthworms is common in these very sandy soils, unless a special effort is made to add organic matter to the soil through cover cropping and additions of organic materials. Earthworms can flourish in sandy soils if sufficient organic residues are provided through cover cropping and the addition of manures and composts.

Yields. Yield data from three orchards under different management and cultural practices cannot be used to draw valid conclusions about the effectiveness of any one cultural or management practice; nor do these data reflect the much more complex picture of comparative profitability. However, yields can be seen as general indicators of the viability of orchard systems. In 1990 all three of the observation orchards produced within 20 pounds of 2,100 pounds of 'Nonpareils' per acre. In 1989, with less favor-

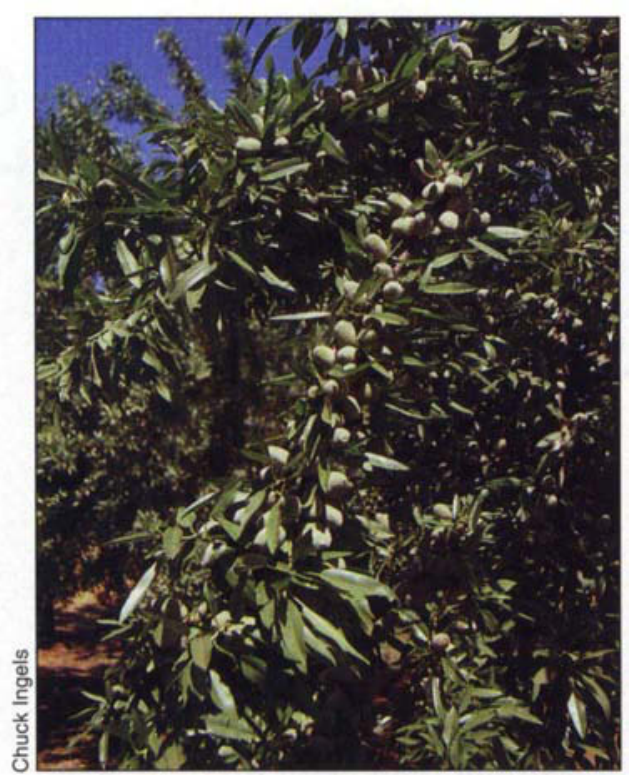

In the absence of springtime diseases, the organic orchard's yields were comparable to yields of the low-input and control orchards.

able weather conditions, the organic orchard produced about $20 \%$ less than the two sprayed orchards. Organic orchards can be maintained at good fertility and insect pests can be effectively controlled, but the limiting factor often is springtime diseases. Severity of these diseases is roughly proportional to the amount and duration of rain at bloom and postbloom. We lack effective bloomtime disease controls for organic orchards. Blossom brown rot (Monilinia laxa) and shot hole (Wilsonomyces carpophilus) are the two most damaging diseases, and are the most likely to reduce crop yields.

\section{Management with fewer pesticides}

This whole-farm comparison looked at the orchard systems, and not at individual pest-prey relationships within the systems. Organic and lowinput farmers and their pest control advisors insist that the whole system must be in place to effective, and that manipulating part of the system will not give the same beneficial result achieved with a whole system. An integral part of the system is a wellmanaged cover crop as a refuge for beneficial insects. This area of the San Joaquin Valley has a good supply of water, which makes cover-crop growing affordable. Water supplies and costs could be limiting in other growing regions. Similar results could be expected in other areas of California if the pest and beneficial complexes and timing are similar to this area. Similar approaches should be tried cautiously in other areas. Growers' experience has been that several years may be required to establish a balanced and effective orchard system.

Future research could be directed toward better identifying the role of each of the many generalist predators present in the orchards. Then perhaps the orchard systems could be modified to encourage the more effective predators.

Sanitation is extremely important in managing NOW. Winter mummy counts of more than one to two mummies per tree often lead to high NOW reject percentages at harvest. Past UC research has demonstrated good correlations between mummy counts above one per tree and increased harvest damage. The same results have been seen in this comparison. High NOW damage followed high mummy counts in the conventional orchard in the first year of the study, even though insecticides were used. However, in some years high mummy counts in the lowinput and organic orchards did not result in high NOW rejects at harvest. This confirms the contention of organic growers that mummy removal is not important in an almond orchard that has a high level of biological control.

Peach twig borer may damage the almond kernel from hull split through harvest. A number of formulations of Bacillus thuringiensis are now marketed for PTB control without disrupting beneficials. The conventional orchard has used $\mathrm{Bt}$, but neither the organic nor the low-input orchards has needed to use a pesticide for PTB control. Peach twig borers are trapped in these orchards, but damage is low.

Recently the California gray field ant, or "crazy ant," has been reported to be a good predator of PTB, and pest control advisors have observed this ant feeding on PTB in almond trees. This ant is commonly found on the cover crop, on the orchard floor, and in the almond trees. The California gray field ant has been observed frequently in these orchards, but no monitoring of its numbers has been done. 
Growers often feel that it is imperative to spray for control of twospotted spider mites and San Jose scale. In the low-input and organic orchards, spraying has not been necessary.

Many almond growers are now using low-input methods with similar good results. They are demonstrating that 'Nonpareil' almonds in the northern San Joaquin Valley can be successfully produced without an insecticide program. Careful winter mummy removal and mummy destruction is very important, especially when starting the transition process. Good covercrop management provides a habitat for beneficial arthropods, and biological control is enhanced if harsh pesticides are not used.

The steps to reducing pesticide inputs that we have found in this study and through the experience of successful growers are:

1. Elimination of in-season insecticide sprays by practicing good winter sanitation and mummy destruction.

2. Establishment of a good cover crop and mowing middles alternately.

3. Monitoring pests, especially scale, very carefully and not using disruptive insecticide sprays.

4. Using two Bt applications at bloom rather than an organophosphate plus oil dormant spray.

5. Using oil dormant spray if needed for scale and mite egg control.

6. Introducing the navel orangeworm parasite Goniozus legneri, if needed, when converting to lower input.

7. Harvesting promptly.

The system outlined in this report may not work for growers throughout California or eliminate all pesticides in almond orchards. However, for many growers these practices will comprise an integrated program of cultural, biological and chemical pest control. These practices also add resilience and inertia to the orchard system, so that the biological balance is resistant to disturbance.

L.C. Hendricks is Farm Advisor, Merced County Cooperative County.

\title{
Crop and farm diversification provide social benefits
}

\author{
Gary W. Johnston $\square$ Suzanne Vaupel $\square \quad$ Franz R. Kegel \\ Melissa Cadet
}

Agronomic and economic benefits of diversification have been well documented, but social benefits are less well known. Two recent California studies show that diversity of crops and farm enterprises creates year-round or extended season employment for farmworkers. Additional strategies for doing so are paced work, selective mechanization, new technologies, break-even crops and coordinating work with other farmers or local industries. Workers employed on a year-round basis or for a longer season have higher incomes, more employerpaid benefits and can provide a better standard of living for their families than their seasonal counterparts. Farmers have found many benefits from a year-round or extended employment system. Some of these are increased worker availability, increased productivity and dependability, less need for worker training and increased personal satisfaction.

For many years, growers have used crop diversification to improve soils and increase profits, but recently farmers have found additional benefits for their employees. While its agronomic and economic benefits are well known, the social benefits of diversification have received relatively little attention. Diversification strategies include rotating to other crops, double cropping and intercropping.

This article reports on two studies of crop diversification systems and employment patterns. The first study investigated the effect of multiple cropping and crop rotation systems of San Joaquin County farmers on farm employment. The second study con- sists of case studies of three farms (in the Coachella Valley, the Sacramento Valley and the North Coast) that intentionally diversified in part to provide year-round employment to seasonal workers. These studies show economic benefits for both growers and farmworkers.

Crop diversification systems also tend to be more agronomically stable and resilient. In its 1989 study, Alternative Agriculture, the National Research Council identified some of the common advantages found in most diverse systems: reduced disease, weed and insect pressures; reduced need for nitrogen fertilizer; reduced erosion; increased soil fertility and increased yields.

Diversification also can provide habitat for beneficial insects and reduces pest numbers by rendering host crops less apparent for colonization by pests. Diversification increases economic stability by reducing financial risk, stabilizing farm income, and increasing choice of farm practices.

Social benefits from diversification result from the opportunity to stabilize employment through an extended onfarm work season. The work force at most farms consists of a group of core workers (usually referred to as "permanent," "regular" or "year-round" workers) and a larger number of seasonal and casual workers, who are often brought to the ranch by farm labor contractors (FLCs). A high degree of turnover has been common among seasonal and casual workers. In a year-round operation, the employment system shifts to a more stable system with fewer workers employed over a longer period of time.

\section{San Joaquin study}

San Joaquin County commercial farmers normally grow three or more 